Editorial

\title{
OPA en 2012
}

\section{OPA in 2012}

Este cuarto número de OPA completa el volumen 45 de la revista, publicado en este año 2012. Gracias al apoyo de muchos, la revista ha seguido creciendo en este año, y los cuatro números publicados sin duda mantienen, si no mejoran, calidad de la revista.

Comenzamos el año publicando en marzo la segunda colección de trabajos ligados al congreso 37th Annual European Meeting on Atmospheric Studies by Optical Methods - AMASOM, celebrado en Valladolid (España). En ese mismo número incluimos en el editorial el listado de todos los revisores que han actuado para OPA en el periodo 2006-2011. De nuevo mi profundo agradecimiento. En el segundo número del año publicamos una excelente colección de trabajos ligados al congreso VII Reunión Nacional de Optoelectrónica, celebrado en Santander (España). El tercer número (septiembre) incluyó asimismo otra sección especial dedicada a contribuciones relacionadas con el congreso XII Encuentro Nacional de Óptica - ENO y III Conferencia Andina y del Caribe en Óptica y sus Aplicaciones - CANCOA, celebrado en Barranquilla (Colombia). En este último número de diciembre, incluimos también una pequeña sección especial con cuatro contribuciones relacionadas con el VI Taller de Mediciones Lidar en Latino-America. Todos estos números han contado asimismo con un total de 13 contribuciones publicadas en la sección regular de la revista.

Quiero destacar y agradecer especialmente las contribuciones de los colegas latino-americanos. Desde hace años deseamos abrir la revista a nuestros colegas del otro lado del Atlántico, y en este año esto se ha convertido en una fuerte realidad. Los trabajos relacionados con los congresos ENO - CANCOA y el taller lidar así lo demuestran, así como el creciente número de trabajos de colegas mexicanos, sin duda estimulados por el reciente acuerdo de
SEDOPTICA con AMO - Asociación Mexicana de Óptica. Sin duda esta actividad se ampliará en el futuro, y desde OPA estamos muy satisfechos de poder contribuir a estrechar los lazos de la comunidad latino-americana en el campo de la Óptica y la Fotónica.

Es un objetivo del Comité Editoral de OPA alcanzar que la revista obtenga el índice de impacto. Para ello es imprescindible que la revista alcance un índice de citas apreciable. En la Fig. 1 adjunta se muestra la evolución de las citas a OPA desde el año 2007, año en que se incorporó a la base de datos Scopus. Se observa la tendencia creciente, tanto en el número total de citas como, lo que resulta más interesante, el número de citas externas (es decir, citas en los que el documento que cita no tiene autores comunes con las referencia citada). A pesar de ello, estos números de citas son muy modestos, por lo que seguimos animando a todos los lectores de OPA a considerar los artículos aquí publicados como referencia en sus publicaciones en otras revistas. Sin duda, aumentar estos registros de citas ayudará a obtener en un futuro próximo el índice de impacto.

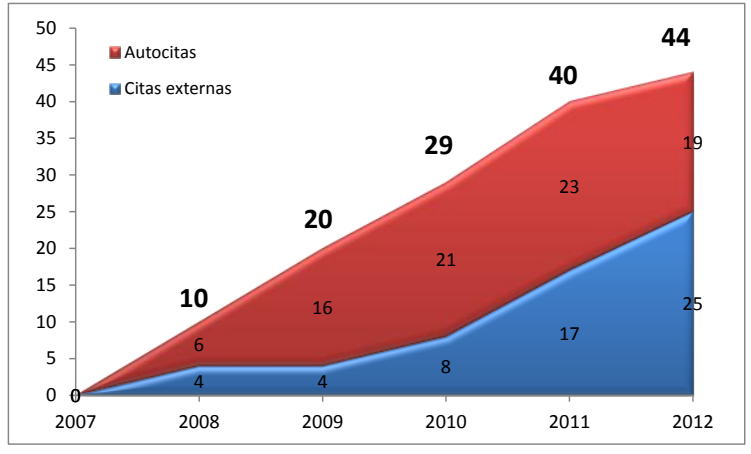

Fig. 1. Evolución de las citas a trabajos de OPA desde su incorporación a la base de datos Scopus (datos consultados en www.scopus.com, 19/12/2012). 
No quiero terminar sin tener un recuerdo entrañable para cuatro personas muy relevantes para la Óptica en España, y para SEDOPTICA en particular, y que lamentablemente nos han dejado en este año: Pedro Mejías, Carlos GómezReino, Lorenzo Plaza y Carlos Illueca. Este número está a ellos dedicado. En este propio número incluimos dos reseñas dedicadas a Pedro Mejías y Lorenzo Plaza, escritas por sus colaboradores Julio Serna y Mariano Aguilar respectivamente. En próximos números incluiremos otras dedicadas a Carlos GómezReino y Carlos Illueca.

\section{Ignacio Moreno}

Editor de Óptica Pura y Aplicada - OPA 